\title{
Del colonialismo a la Primera Guerra Mundial Desestructuración de los pueblos de África'
}

Axel Riveros Vera ${ }^{2}$

Universidad Autónoma de Colombia

\section{Resumen}

El presente avance de investigación ofrece una aproximación teórica al origen y expansión del colonialismo de finales de siglo XIX por parte de Europa en África, dentro de un enfoque intercultural que se viene construyendo en grupos académicos y comunidades sociales que han vivido un proceso de silenciamiento histórico en nuestro medio y en la mayoría de los países de América Latina. Se da un acercamiento teórico al imperialismo y al colonialismo, para luego estudiar la configuración del espacio geográfico y social de África. Se termina con unas conclusiones provisionales derivadas del trabajo en curso.

Palabras clave: Interculturalidad, imperialismo, colonialismo, supremacía racial, nacionalismo, cultura, liberación.

I Este documento hace parte de la propuesta investigativa de tesis doctoral "Historia crítica del pensamiento intercultural y decolonial en América Latina" que se viene trabajando en la Universidad ARCIS en Santiago de Chile.

2 Especialista en Economía Internacional y en Pensamiento Educativo y Filosófico en América Latina, Magister en Educación, docente de historia Universidad Autónoma de Colombia . Dirección electrónica: contextomundial@hotmail.com 


\title{
From Colonialism to the First World War. Deconstruction of African towns
}

\begin{abstract}
The present research assessment offers a theoretical approach to the origin and expansion of colonialism at the end of 19th century of Europe in Africa, within an intercultural approach, which has been built by academic groups and social communities which have lived a process of historical silence in our region and in most of the countries of Latin America. There's a theoretical approach to Imperialism and Colonialism in order to study the configuration to the geographical and social space in Africa. It ends with some provisional conclusions derivated from the current work.
\end{abstract}

Key words: Interculturality, Imperialism, colonialism, racial supremacy, nationalism, culture, liberation.

\section{Do colonialismo à Primeira Guerra Mundial Desestruturação dos povos de África.}

\section{Resumo}

O presente relatório de pesquisa oferece uma abordagem teórica sobre a origem e expansão do Colonialismo de finais do século XIX por parte da Europa na África, dentro de um enfoque intercultural. Tal enfoque vem se construindo em grupos acadêmicos e comunidades sociais que tem vivido um processo de silenciamento histórico em nosso meio e na maior parte dos países de América Latina. Há uma aproximação teórica ao Imperialismo e ao Colonialismo, para posteriormente discutirmos a configuração do espaço geográfico e social da África. Termina-se com algumas conclusões provisórias derivadas do trabalho em andamento.

Palavras chave : Interculturalidade, imperialismo, colonialismo, supremacia racial, nacionalismo, cultura, liberação.

«El descubrimiento y la conquista de América por los europeos introducen una importante variante. Por primera vez, y por razones religiosas, el colonizador se interroga a sí mismo sobre la justicia de la empresa colonizadora y, en acalorados debates de juristas y teólogos, se arma de razones, humanas y divinas, para justificar sus conquistas. Desde entonces, sin dejar de ser lo que fue siempre, es decir, un acto de fuerza y de rapiña, la colonización se atribuye a sí misma una misión evangelizadora y civilizadora: desanimalizar a quienes viven en estado feral y humanizarlos gracias al cristianismo y a la cultura occidental que aquél inspira. Para que este objetivo tenga algún viso de realidad es imprescindible establecer como un hecho indiscutible, científico, que el colonizado carece de los conocimientos y las luces indis- 
pensables para juzgar por sí mismo lo que más le conviene, pues se trata de un ser desvalido y primario cuyos intereses y conveniencias son mejor percibidos por la potencia que a partir de ahora ejercerá sobre él la tutela colonial, una forma de autoridad benévola».

Mario Vargas Llosa, Congo belga: historia de un genocidio, enero 10 del 2009

En el aniversario de los 100 años de la Primera Guerra Mundial, es importante realizar un acercamiento a algunas situaciones y eventos que se vivieron previos a esa confrontación mundial. Uno de esos tópicos que pretende abordar la presente comunicación tiene que ver con la colonización y el colonialismo que se impulsan en las últimas décadas del siglo XIX fundamentalmente en África, continente en el cual Alemania depositara sus ambiciones coloniales compitiendo con el Imperio Británico. Las motivaciones y las incidencias de ese proceso serán presentados en este documento.

Hay varios hechos recientes que se relacionan con las temáticas que se van a exponer, una de ellas es que Argentina se ve obligada a ceder sobre su "deuda soberana" ante el juez, Thomas Griesa, de Estados Unidos (2012 y 20I4), quien desconoce las acciones llevadas por ese gobierno para el pago de unos bonos de endeudamiento; esto nos lleva a preguntarnos ¿cómo se da y se manifiesta el colonialismo? Provisionalmente se puede responder que esas situaciones y otras son manifestaciones de un viejo colonialismo y de un "colonialismo interno" del cual no se ven sus agentes y acciones externas. Unos «fondos» han condicionado los pagos de esos bonos de deuda pública, son administradores de capital de riesgo que se dedican a comprar títulos de deuda pública, y bajo precio en economías en problemas, como lo fue la de Argentina en 200।; de este modo se pueden accionar judicialmente para el cobro total de los bonos más los intereses por los años adeudados, desconociendo de paso las negociaciones ${ }^{3}$.

Esto correspondería al colonialismo interno, el investigador mexicano Pablo González Casanova al respecto señala:

«primero, que el colonialismo interno se da en el terreno económico, político, social y cultural; segundo, cómo evoluciona a lo largo de la historia del Estadonación y el capitalismo; tercero, cómo se relaciona con las alternativas emergentes, sistémicas y antisistémicas, en particular las que conciernen a "la resistencia" y "la construcción de autonomías" dentro del Estado-nación, así como a la creación de vínculos (o a la ausencia de estos) con los movimientos y fuerzas nacionales e internacionales de la democracia, la liberación y el socialismo ${ }^{4} \gg$.

3 Fondos Buitre. Expertos cuestionaron en EEUU el fallo de Griesa contra la Argentina http://www.telam.com.ar/notas/20 I 4 I 0/80953-griesa-fondos-buitre-expertos-estados-unidos.html Consulta: julio 23 del 2014

4 González Casanova, Pablo. "Colonialismo interno, una redefinición" en La teoría marxista hoy, problemas y perspectivas, Borón, Amadeo y González (comps.), Buenos Aires: Clacso, 2006, pág. 409. 
El colonialismo interno muestra relaciones de comercio inequitativo -desigualdad y explotacióntanto en lo local como en lo internacional. Hay que reconocer que existen procesos coloniales en el interior del Estado-nación, a partir de los cuales se renuevan muchas de las estructuras coloniales internas que eran propias del dominio colonial o burgués. Se da un proceso de contradicciones entre el gobierno nacional y las nacionalidades neocolonizadas, algunos sectores se oponen a las luchas de las "minorías nacionales", "las nacionalidades" o "los pueblos originales", sin que la correlación de fuerzas subsistente sea alterada y sin que se les permita a estos últimos modificarla en un sentido liberador, que incluya la desaparición de las relaciones coloniales al interior de ese Estado.

La definición del colonialismo interno está ligada a fenómenos de conquista, en que las poblaciones de nativos -y mestizos- no son exterminadas y forman parte, primero, del Estado colonizador y, después, del Estado que adquiere una independencia formal, o de transición a las últimas formas adoptadas por el capitalismo.

Según González Casanova en la actualidad los pueblos, minorías o naciones colonizados por el Estado-nación sufren entre otras las siguientes condiciones: I. habitan en un territorio sin gobierno propio; se encuentran en situación de desigualdad frente a las elites de las de las clases y etnias dominantes; 2. su administración y justicia jurídico-política dependen de las etnias dominantes, a las burguesías y oligarquías del gobierno central o a los aliados y subordinados del mismo; 3. sus habitantes no participan en los más altos cargos políticos y militares del gobierno central, salvo en condición de "asimilados"; y 4. los derechos de sus habitantes y su situación económica, política, social y cultural son regulados e impuestos por el gobierno central".

La política económica globalizadora redefine el protagonismo de las empresas y los países con sus redes internacionales, intranacionales y transnacionales. En cuanto a las relaciones de dominación y explotación regional, las redes articulan los distintos tipos de comercio inequitativo y de colonialismo, así como las formas de explotación de los trabajadores, o las distintas políticas de participación y exclusión, de distribución y estratificación por sectores, empleos, regiones ${ }^{6}$, proceso muy similar que se dio a finales del siglo XIX, en la relación de las potencias con respecto a África y Asia.

Dentro de esta perspectiva, el abordaje desde el cual se hará la presente lectura será desde un campo de reflexión que se ha construido en la última década en América Latina: la «interculturalidad», que implica un proyecto político, cultural y epistémico desde el sur. Por lo tanto, exige una revisión de hechos y procesos que en el ámbito internacional regional y local han incidido y marcado la realidad de nuestra región. "La interculturalidad despeja horizontes y abre caminos que enfrentan al colonialismo aún presente, e invitan a crear posturas y condiciones, relaciones y estructuras nuevas y distintas"'.

5 Ibídem, pág. 410.

6 Ibídem, pág. 425.

7 Walsh, Catherine. Interculturalidad, Estado, sociedad luchas (de)coloniales de nuestra época. Quito: Universidad Andina Simón Bolívar / Ediciones Abya-Yala, marzo 2009, pág. 14. 
La interculturalidad es un proyecto que reflexiona sobre los patrones de poder que mantienen y siguen reproduciendo el racismo, la racialización, la deshumanización de algunos y la subalternización de seres, saberes y formas de vivir, ejemplo de ésto fue el proyecto "civilizador" que en apariencia se trató de imponer a través del colonialismo en África. De tal forma, que el objetivo central de este trabajo es el de "reflexionar desde una perspectiva «intercultural» sobre algunos elementos del colonialismo desarrollado por los países europeos a finales del siglo XIX en otros espacios".

Este documento es un balance y una reflexión críticas sobre la historia vivida antes de 1914 , y los cambios sociales derivados de un modelo social y cultural impuesto desde Occidente; esto permite comprender en parte la transformación de las sociedades fuera de Europa y sobre la desestructuración social que se correspondió a unos intereses políticos y económicos. Es decir, un objetivo complementario que se propone es el de "comprender algunos aspectos del colonialismo y de la experiencia colonial en África", estableciendo las posibles particularidades, continuidades y rupturas de ese proceso. Hay una revisión bibliográfica inicial sin entrar a debates conceptuales, es un abordaje de la "experiencia colonial" en sociedades afectadas por Occidente.

\section{Precisiones iniciales}

El colonialismo es una realidad que ha tenido diversas manifestaciones en los últimos siglos y en diferentes partes del planeta, a él se hace referencia de una manera particular a partir de las últimas décadas del siglo XIX y como hecho histórico sirvió de justificación para la ocupación de territorios diferentes a los de Europa y Estados Unidos. En nombre de una aparente superioridad y de intereses en favor de la civilización occidental y del progreso, se impuso la explotación económica y la dominación política de muchos países de Asia y África, como cierre del expansionismo capitalista iniciado a lo largo del siglo XV.

El término "colonialismo" tiene connotaciones particulares en las primeras décadas del siglo XX, ya que en su conceptualización se inscriben una serie de doctrinas y de intenciones políticas que buscaban justificar el dominio de Europa -países del Norte- sobre otros pueblos. La "colonización" significa la acción de grupos humanos sobre territorios alejados de su lugar de origen, posteriormente el colonialismo corresponde a un momento histórico que implica unas formas y unas actuaciones que se expresan en un "ser", es decir, la colonización y el colonialismo van configurando una "colonialidad del ser" que es diferente de acuerdo con las actuaciones que hacen unos otros sobre pueblos y seres concretos en determinados momentos históricos.

Aunque el colonialismo hace parte del Imperialismo, no se deben confundir; Lenin consideró las últimas consecuencias de la doctrina de la acumulación de capital y denunció el imperialismo como dominación colonialista, pero también como el "estadio superior del capitalismo", impulsado por la misma dinámica del sistema económico para superar o atenuar sus contradicciones internas.

8 Lenin, Imperialismo fase superior del capitalismo. (ensayo popular). Pekín: Ediciones en Lenguas Extranjeras, 1975. 
Ahora bien, el imperio como término hace referencia a la suprema autoridad o control que ejerce una sociedad con estructuras sociales y políticas particulares (que se consideran complejas) sobre pueblos que, en apariencia no están tan estructurados desde los parámetros de Europa, en los que se usa como medio la fuerza para avasallarlos. Pero la expansión europea decimonónica dio vida a nuevos tipos de imperios integrados por la metrópoli y los territorios de ella dependientes. El imperialismo en la actualidad -al que se le denomina globalización- "no exige el empleo de la fuerza militar para su constitución y ni siquiera la dominación política directa, la esencia está determinada por la explotación económica del país sometido, tanto de sus recursos naturales como del trabajo de sus habitantes, en beneficio de la metrópoli"'.

El imperialismo se impone en la segunda mitad del siglo XIX, cuando las fuerzas productivas, en especial la industria, alcanzaron un alto nivel de desarrollo, que hizo necesaria la búsqueda de nuevos mercados para los productos, materias primas más abundantes y baratas, y un espacio económico en el que pudieran ampliarse los capitales excedentes. Debido a las rivalidades entre las potencias europeas, las ventajas podían alcanzarse en países lejanos, sin estructuras complejas sociales y políticas, y sin medios técnicos para resistir el asalto de los países industrializados ${ }^{10}$.

A pesar de que el colonialismo -el que se ejerció en África y Asia- tiene manifestaciones diferentes, hay unas características comunes que se pueden reconocer:

I. El invasor integra parte de su sociedad a la población y la consolida como grupo hegemónico o dominante sobre el pueblo invadido. Existe un vínculo estrecho entre el grupo hegemónico y la metrópoli. Ese grupo se sigue considerando ciudadano de la metrópoli y reclama para sí los beneficios de su país de procedencia. Hay una jerarquización social en donde los nativos que hacen parte de la administración colonial reciben algunos privilegios (estudio en la metrópoli, cargos públicos, concesiones, etc.) el resto de la población no tiene el más mínimo reconocimiento social frente a los invasores.

2. Se establecen en las regiones sometidas, autoridades que son delegaciones del gobierno de la metrópoli, son una prolongación de las políticas de la metrópoli. En ocasiones las autoridades entregan la administración de los territorios conquistados a compañías que se encargan de la explotación y de hacer justicia a través de ejércitos privados, hay una sobreexplotación de la mano de obra nativa.

3. Dominación por parte de una minoría extranjera, la cual ejerce una pretendida superioridad racial y cultural sobre una mayoría nativa a la que se considera inferior. La cultura de los invasores se intenta imponer a los invadidos, entre los grupos hegemónicos se mantienen los privilegios de la cultura. Se transmiten e imponen algunas nociones a los nativos.

4. Contacto entre dos o más sociedades con sus referentes culturales, la visión occidental judeocristiana se considera superior, desconociendo el contenido simbólico religioso de otros pueblos.

9 Madrilejos, Mateo. Colonialismo y Necolonialismo. Barcelona: Salvat Editores. 1975, págs. 19-20.

I0 Ibídem, pág. 20. 
La "civilización" europea se considera más avanzada y se impone en todos los órdenes sobre las culturas autóctonas, a través de diversas formas de organización política y administratival!.

5. Dentro del proceso Imperialista en los países del Norte se da el surgimiento del capital financiero, que se produce por la unión del capital bancario e industrial, en donde el primero subordina al segundo, dando nacimiento a ese capital financiero. Se constituyen los monopolios que dependen de ese capital financiero. Además, hay una necesidad de transferir capital de la metrópoli a la periferia. Antes había exportaciones de mercancías ahora es la exportación de capitales, a veces recibe el nombre de inversión extranjera'2.

Es importante recordar que Hispanoamérica fue colonia de las Españas con una arbitraria organización territorial, pero que se inscribió dentro de un modelo inicial de colonialismo, durante más de tres siglos, los reyes y sus autoridades trataron de dar un orden en nuestros espacios, pero que se corresponde al desarrollo y la expansión capitalista; era necesario consolidar un mercado y un grado de intercambio comercial en el cual concurrían otros países europeos. Esto fue preámbulo para la colonización y el colonialismo bajo el imperialismo durante el siglo XIX.

El sistema mercantilista, que hizo de las colonias meras dependencias económicas de la metrópoli, se benefició por los procesos de independencia nacionalista de Estados Unidos 1776 y la emancipación de las colonias hispanoamericanas 1810.

Gran Bretaña tenía un proceso acelerado de Revolución Industrial frente al cual ningún país podía competir, promovió el librecambismo que favorecía la supremacía fundada sobre el dominio de los mares. En la segunda mitad del siglo XIX, a partir de 1870, se dio el gran salto hacia delante de la expansión colonialista europea. Gran Bretaña y Francia extendieron sus dominios en Asia y se lanzaron a la aventura de la conquista africana, por otro lado, la Alemania de Bismarck promovió y patrocinó el reparto de África'3.

La explicación común es que se dio una segunda expansión de Europa en territorios diferentes a los de América y del Caribe, las colonias en nuestras tierras habían sido de «asentamiento»; las nuevas eran de «ocupación», además el número de potencias europeas con colonias aumentó en la medida en que también se extendían las áreas de control. "En 1914 había diez, incluyendo los Estados Unidos, una ex colonia convertida en potencia imperial"|l.

Entre 1890 y 1900, las cuestiones coloniales estaban asociadas al prestigio y a la seguridad de los Estados europeos, asunto que se tradujo en las negociaciones internacionales. Para las generaciones que vivieron bajo el reinado de la reina Victoria, consideraban que la colonización era una actividad específicamente británica.

\footnotetext{
II Ibídem, págs. 20 y 21 , y RUBIO, Rocío. Imperialismo y colonialismo. Bogotá: Editorial Voluntad. 2003, pág. 10.

12 Lenin, Op.Cit, capítulo II, los bancos y su nuevo papel.

13 Madrilejos, Mateo. Op.Cit., págs. 22-23.

14 Fieldhouse, D.K. Economía e Imperio. La expansión de Europa. México: Siglo Veintiuno Editores. 1977. Pág. 8.
} 
Los enfoques sobre el imperialismo se inscriben inicialmente dentro de una concepción «eurocéntrica», ya que se deriva de las necesidades de Europa y de sus desarrollos económicos, correspondientes a un proceso acelerado de industrialización. "Las colonias podían extender el comercio metropolitano, y, por tanto, la producción abriendo nuevos y seguros mercados y proporcionando nuevas fuentes de materias primas"'15.

Otras interpretaciones tienen que ver con los intereses políticos, se habla del imperialismo con «pensamiento oficial», que corresponde a las iniciativas de los gobernantes y líderes superiores, que consideraban que dentro del sistema de alianzas era necesario contar con posesiones ultramarinas, para posibles negociaciones estratégicas con el objeto de garantizar esa seguridad. Otra perspectiva se corresponde a ese «imperialismo de masas», que se asocia a la presión de ciertos grupos que condicionaban la actuación de los dirigentes. A estas explicaciones hay que añadír otra perspectiva, que es la «periférica» en la que ciertas condiciones de las regiones hicieron posible la presencia de ese imperialismo y que articuló esos espacios a un escenario más amplio de intercambios y relaciones ${ }^{16}$.

Las razones que explican la apropiación de África por parte de los europeos son varias, algunas señalan que la presión demográfica europea, produjo una emigración ultramarina de un millón y medio de personas por año; pero la verdad es que el colonialismo fue impulsado por países que no contaban con un excedente demográfico.

"En Francia se esgrimió con orgullo su misión civilisatrice (misión civilizadora), mientras que en Gran Bretaña, por boca del escritor Rudyard Kipling ( 1865-1936), se proclamaba que la conquista y explotación de las colonias formaban parte de «la pesada carga del hombre blanco»" "17.

Estos argumentos fueron rebatidos posteriormente por la lucha y el pensamiento anticoloniales. Hasta la década de los 70 del siglo XX, Portugal como uno de los últimos países colonialistas, disimuló sus objetivos mercantiles o estratégicos, e insistió como en antaño en los beneficios aportados por el "pacto colonial" a los países colonizados.

La expansión europea se produjo en una coyuntura económica de recesión que favoreció el retorno a un moderado proteccionismo. El desarrollo industrial de Francia y Alemania, se volvió una amenaza para los británicos, los cuales consideraron las colonias como puntos de apoyo importantes. Joseph Chamberlain (ex ministro de las Colonias) y Cecil J. Rhodes en Gran Bretaña promovieron el colonialismo por razones económicas.

\footnotetext{
Ibídem, pág. II.

Ibídem, págs. 12-13.

7 Madrilejos, Mateo. Op.Cit., pág. 25.
} 


\section{La Expansión Colonial}

(superficie en millones de kilómetros cuadrados y población en millones de habitantes)

\begin{tabular}{|c|c|c|c|c|c|c|c|c|}
\hline \multirow[t]{3}{*}{ país } & \multicolumn{4}{|c|}{ Colonias } & \multirow{2}{*}{\multicolumn{2}{|c|}{$\frac{\text { Metrópolis }}{1914}$}} & \multirow{2}{*}{\multicolumn{2}{|c|}{$\begin{array}{c}\text { Total } \\
1914\end{array}$}} \\
\hline & \multicolumn{2}{|c|}{1876} & \multicolumn{2}{|c|}{1914} & & & & \\
\hline & Superf. & Pobl. & Superf. & Pobl. & Superf. & Pobl. & Superf. & Pobl. \\
\hline Reino Unido & 22,5 & 251,9 & 33,5 & 393,5 & 0,3 & 46,5 & 33,8 & 440,0 \\
\hline Rusia & 17,0 & 15,9 & 17,4 & 33,2 & 5,4 & 136,2 & 22,8 & 169,4 \\
\hline Francia & 0,9 & 6,0 & 10,6 & 55,5 & 0,5 & 39,6 & $\mid 1,1$ & 95,1 \\
\hline Alemania & --- & --- & 2,9 & 12,3 & 0,5 & 64,9 & 3,4 & 77,2 \\
\hline Estados Unidos & --- & --- & 0,3 & 9,7 & 9,4 & 97,0 & 9,7 & 106,7 \\
\hline Japón & --- & -- & 0,3 & 19,2 & 0,4 & 53,0 & 0,7 & 72,2 \\
\hline $\begin{array}{l}\text { Total de las seis } \\
\text { potencias }\end{array}$ & 40,4 & 273,8 & 65,0 & 523,4 & 16,5 & 437,2 & 81,5 & 960,6 \\
\hline \multicolumn{7}{|c|}{ Colonias de otras potencias } & 99,9 & 45,3 \\
\hline \multicolumn{7}{|c|}{ Semicolonias (Persia, China, Turquía) } & 14,5 & 361,2 \\
\hline \multicolumn{7}{|l|}{ Otros países } & 28,0 & 289,9 \\
\hline \multicolumn{7}{|c|}{ Superficie y población totales de la tierra } & 133,9 & 1657,0 \\
\hline
\end{tabular}

Tomado de Gutierrez Contreras, Francisco. Nación, nacionalidad, nacionalismo. Barcelona: Temas Clave Salvat. 1980.

Los países de la Europa industrializada, impulsaron la expansión porque necesitaban productos alimenticios, materias primas, nuevas fuentes de energía y nuevos mercados para su industria, con el fin de evitar la recesión económica. La expansión colonial tuvo beneficios políticos en las metrópolis, pues redujo las tensiones internas y promovió un patriotismo -asociado al imperialismo- que reivindicó el dominio sobre otros pueblos. El sometimiento de la India, aseguraba el funcionamiento de las fábricas de los Middlands (tierras medias de Inglaterra). Hubo cierta mejora en las condiciones de vida de los obreros de los centros ya que la explotación se acentuó en las colonias ${ }^{18}$.

Para algunos líderes como el inglés Joseph Chamberlain, las llamadas colonias tropicales fueron mercados esenciales para los excedentes de la industria europea, esto contuvo la revolución social. Los franceses y británicos argumentaron que las colonias, al proporcionar materias primas y alimentos baratos, impedían los altos beneficios de los monopolios. "En suma consideraban que aquellas no sólo eran una solución para superar las rivalidades entre las grandes potencias, sino también para

I8 Ibídem, págs. 25-26. 
resolver la mayor parte de los problemas sociales y económicos de una Europa industrializada y proteccionista"'19.

\section{La llegada al Imperialismo y expansión del colonialismo}

El Imperialismo y el colonialismo hacen parte de un mismo proceso que parte de Europa, se derivan del desarrollo del capitalismo, de la revolución industrial y de la consolidación de un mercado mundial. Se entiende por colonialismo el hecho de que las potencias del mundo, como Inglaterra, Francia, Alemania, Bélgica y Japón, entre otros, ejercieran un dominio sobre ciertos territorios, que eran más débiles económica y militarmente. Por otra parte, el imperialismo es el término que expresa las modificaciones del capitalismo al irse perfilando el capital financiero y muestra el grado de dominio sobre estas zonas mediante el control económico y político; en 1914 la ocupación colonial se extendía al 90\% de África, al 95\% de Oceanía y 56\% de Asia.

Existen muchas razones económicas por las cuales se produjo el colonialismo y están asociadas a los propios intereses del capitalismo mundial; la burguesía ambicionó los elementos necesarios para las industrias y ello empujo a los respectivos países a realizar empresas coloniales, así mismo, el capital financiero pretendía mayores beneficios.

Lo que se buscaba en las colonias eran materias primas y energía; los países industrializados necesitaban acero o carbón, también se requerían otros productos tropicales como maderas, caucho y marfil. También se buscaban mercados, para colocar sus productos manufacturados (máquinas, herramientas, etc.) y comprar productos primarios (hierro y otros minerales, algodón, petróleo, alimentos) con evidentes ventajas para los países de Europa. Por último, había que trasladar los excedentes de población y de capital de las metrópolis o Estados colonizadores, el crecimiento económico hizo que descendiera la mortalidad y las colonias sirvieron como nuevos lugares de residencia ${ }^{20}$.

Ese proceso facilitó el fortalecimiento del nacionalismo europeo, ya que se quiso enaltecer el prestigio de los habitantes de los países del viejo continente, además, en algunas potencias el imperialismo se asoció con la capacidad de conquista y de control de territorios en el extranjero. A esto se sumaron razones estratégicas, como la de garantizar los suministros de materias primas para la fabricación de armamentos, la protección de enclaves costeros y el control de las principales rutas de comercio ${ }^{21}$.

19 Ibídem, pág. 26.

20 Rubio, Rocío (2003). Imperialismo y colonialismo. Bogotá: Editorial Voluntad, págs. 25-26

21 Sánchez Rodríguez, Jesús (20 I4). 19|4. EL QUIEBRE DE LA HISTORIA. Causas y consecuencias de la primera guerra mundial, págs. 39-4I.

http://www.rebelion.org/docs/I86878.pdf

Consulta: julio 23 del 2014 
Sumado a lo anterior, se reorientaba el exceso de capital que se originó con el proceso de industrialización pero no se promovían las actividades manufactureras en las colonias, además se conseguía mano de obra barata en el mercado de trabajo. Los capitales generados se invirtieron en los países colonizados que estaban bajo el control de las oligarquías y burguesías locales (minorías con gran poder económico y político). La falta de organización obrera por parte de los habitantes de las colonias, le garantizaba la estabilidad social y política a los flujos de capitales22.

Ese proceso implicaba el paso del sistema de Estados europeos al sistema mundial y Alemania debía desarrollar una fuerte política internacional, pero antes de 1914 no existía un sistema universal de Estados que garantizara una convivencia pacífica. Se mantenía el sistema en el que las grandes naciones como Inglaterra, Francia, el Reich alemán, Austria-Hungría y Rusia tenían un papel preponderante a pesar de que los viejos problemas no se habían resuelto; ciertas dificultades como "la cuestión del futuro del Imperio Otomano"; la reorganización de los Balcanes ${ }^{23}$ y el control de las rutas marítimas comerciales.

Los políticos se inspiraban en los conceptos de la diplomacia clásica, la preocupación era el establecimiento de un equilibrio de poderes en Europa, pero que se alteraba para beneficiar a las alianzas; pero a la vez se dio una política activa de adquisición de colonias y de territorios a partir de 1890.

A finales de 1885 Inglaterra y Francia impulsan una agresiva política de expansión colonial; se buscaban territorios de ultramar aún libres, a partir de 1894 se sumaron Japón y Estados Unidos. Hasta ese momento los europeos habían dejado todo en manos de los colonizadores y a las empresas coloniales. Se trató de reducir la intervención política y militar, esto explica que Gran Bretaña hacia 1914 tenía solo 100.000 soldados y en los inicios de la Primera Guerra Mundial tiene que reclutar hombres de sus colonias (Canadá, Australia y Nueva Zelanda)24.

Debido al nacionalismo que desembocó en el imperialismo, las potencias europeas buscaron nuevos territorios coloniales; la rivalidad entre los países supuso dejar las formas tradicionales de dominación que se iniciaba desde los puertos en las costas (modelo portugués), hay un enfrentamiento por la conquista del interior y la delimitación de las fronteras de esos territorios. Los tratados de protección firmados por los jefes de las tribus nativas, no servían para ampliar los imperios coloniales, eran necesario ahora negociaciones con las otras potencias rivales.

Este proceso inicia en 188 I cuando Francia se establece en Túnez y dos años después en Annam (Vietnam), Congo y Somalia; entre 1883 y 1884 Bismarck conquista los protectorados de África del Sudeste (hoy Namibia), así como Togo y Camerún. Un caso clave fue la ocupación de Egipto por Inglaterra en 1882, que junto con Francia, se buscaba asegurar los intereses de los acreedores europeos. Inglaterra ejerció la ocupación unilateral mientras que en Francia el parlamento impidió la acción, posteriormente se le exigió a los ingleses retirarse ya que podían afectar la tradicional cultura

22 Rubio, Rocío, Ibídem.

23 Mommsen, Wolfgang J. La época del Imperialismo. México: Siglo Veintiuno Editores. 1978, pág. 137.

24 lbídem, pág. 138. 
del Nilo; al final en Egipto se impone el protectorado inglés 25 . Bismarck desde 1885 impulsó "las aspiraciones de las otras grandes potencias en el terreno político-colonial y desvía las tensiones del sistema europeo de potencias a la periferia6"', aspecto que sería también utilizado durante la Primera Guerra Mundial, "desconocer la crisis sobre las colonias".

En 1885, el proceso colonial no sufre demasiadas transformaciones. En Inglaterra se volvió a las concesiones de las Chartered Companies particulares, como la Imperial British East Africa Company y la British South Africa Company ( 1889 ), para explotar los territorios coloniales y se llegó a un acuerdo con Rusia sobre Afganistán. Bismarck tampoco era partidario de proyectos político-coloniales y proponía una política de autolimitación ante su amenazada posición en el centro de Europa.

"Las grandes potencias europeas, por iniciativa de Bismarck cedieron en el año I 885 el futuro Congo belga a Leopoldo II, rey de los belgas, para su explotación particular, un derecho del que había de abusar bien pronto el rey, a cambio de ciertas concesiones, como el mantenimiento de la «puerta abierta», es decir, el paso libre al comercio de todas las naciones"27.

El problema tenía que ver con el reconocimiento y la organización de la «Association Internationale du Congo»s (AIC), Portugal proponía una ley por la que se creaba la provincia portuguesa del Congo, Bismarck como canciller del Reich, presentó una protesta diplomática en Lisboa y en Londres, a su vez sugirió simultáneamente al gobierno francés la celebración de conversaciones para regularizar la cuestión africana. El 23 de junio de 1884 Bismarck declaró ante el Reichstag que el gobierno imperial sancionaba el proyecto de crear un Estado independiente en el Congo y felicitaba al promotor, el rey belga. El Reich en noviembre reconoce oficialmente a la AIC y se invita a varios países a encontrarse en Berlín para tratar los siguientes puntos:

I. Establecer el librecambio en la cuenca y la desembocadura del Congo.

2. Aplicar el principio de libre navegación en el Níger y el Congo.

3. Definir fórmulas prescriptivas para que las futuras anexiones en el litoral africano obtuvieran automáticamente el reconocimiento internacional28.

Alemania logró un compromiso político-económico, pero no un debate sobre delimitaciones geopolíticas; el 15 de noviembre se da inició a la Conferencia. Llama la atención que Estados Unidos envió delegados a dicho encuentro, también estuvieron representantes de Bélgica, Dinamarca, Alemania, Francia, Gran Bretaña, Italia, Holanda, Noruega, Austria-Hungría, Portugal, Rusia, Suecia,

lbídem, págs. 139-|40.

lbídem, pág. 140.

lbídem, págs. |40-|4|.

28 Bormann, Martin. Entre la cruz y el fetiche. Barcelona: Plaza \& Janes. 1968, págs. 59-60. 
España y Turquía, en cabeza de las potencias se elaboraría el «Acta General de Berlín»; la mayoría de países estarían involucrados en la Primera Guerra Mundial.

"Los Estados participantes garantizaban la libertad del comercio y de la navegación y la colonización en los territorios congoleños, aseguraban idénticos derechos para los agentes belgas de la AIC y los de otras nacionalidades y se declaraban dispuestos al promover la libertad religiosa y el progreso de los nativos bajo el aspecto moral y civilizador"29.

Los diferentes países participantes fueron reconociendo a la AIC como país soberano y de la «Association Internationale du Congo» (AIC) nace un Estado soberano, l'État Indépendant du Congo (EIC), con el rey Leopoldo II de Bélgica como soberano (el 30 de junio de 1960 sería la República Democrática del Congo). La trata de esclavos floreció en el Congo ( 1887), en el Este fue manejada por los árabes y en el Oeste por los blancos ${ }^{30}$.

Entre los años 1885 y 1890, Leopoldo II había invertido todo su capital en la empresa en el Estado del Congo, pero se da un fuerte déficit de los fondos públicos. El Estado tenía que competir con las compañías comerciales por eso decide explotar al país por su cuenta. El I de julio de I 885 el ElC se declara propietario de los bienes sin dueño, posteriormente se da la nacionalización de las plantaciones de caucho, ya que junto al marfil (que ya estaba monopolizado) tenía los precios más altos ${ }^{3 !}$.

Ahora bien, entre las potencias predominaba más la rivalidad que la cooperación; entre 1885 y 1892, los viejos problemas estaban latentes, como la cuestión búlgara que provocaría en 1887 una fuerte crisis en las relaciones germano-rusas. Se propuso la guerra de prevención contra los vecinos, además por previos acuerdos con Rusia el Reich alemán mantenía un acercamiento político con ese país.

La salida de Bismarck en marzo de 1890 significó el cambio del clásico sistema equilibrio entre las potencias europeas. Los países de Europa estaban siendo condicionados por una fuerte opinión pública recargada de nacionalismos. Los intereses imperialistas y coloniales dificultaban mantener el viejo sistema de alianzas. Bismarck había tratado de evitar mediante una política de alianzas que Europa se enfrentara por los nacionalismos.

Los rusos se mantuvieron distanciados de la diplomacia francesa, no querían llegar a la guerra por Alsacia-Lorena. Rusia quería asegurar su frontera occidental desde 1890, año en que inició la colonización de Siberia y del Lejano Oriente. Los ingleses a partir de 1894 asumieron la herencia de la arruinada Imperial Britihs East Africa Company y anexaron a Uganda, esto significaba una nueva fase en la política imperial británica, dicho país se aseguraba territorios estratégicos a través de acuerdos

29 Ibídem, pág. 60.

30 Ibídem, pág. 61.

31 Ibídem, págs. 63-64. 
y se estabiliza el dominio sobre Egipto ${ }^{32}$. Las relaciones entre Alemania e Inglaterra estaban marcadas por una fuerte desconfianza, Alemania sentía que su política internacional era permanentemente rechazada por Inglaterra.

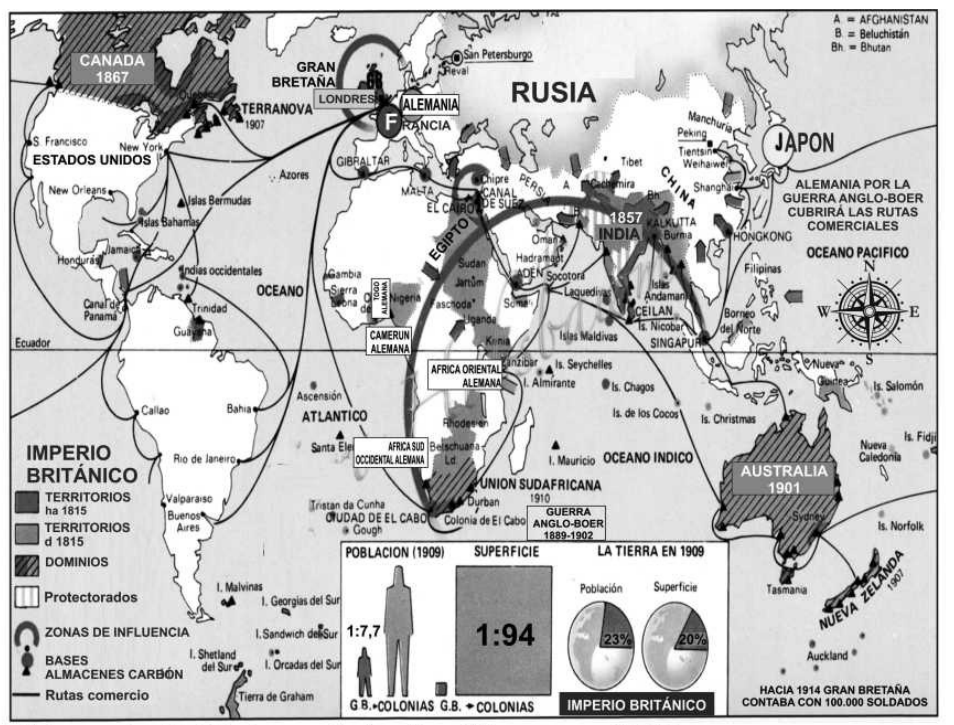

\section{El Imperio Británico y Colonias Alemanas 1914}

[Fig. I. Mapa Imperio Británico y Colonias Alemanas en 1914.Tomado y adaptado de: http://cencahistoriauniversal.files. wordpress.com/20I I/02/hmc-mapa-hco-imperio-britanico-hacia-19/4.jpg]

En medio de las rivalidades, se pasa de la política tradicional de aislamiento a la de las alianzas políticas. Joseph Chamberlain consideraba que la raza anglosajona y la teutona estaban llamadas a gobernar juntas el mundo, por eso, presentó en marzo de 1898 un proyecto de alianza con los alemanes, el país germano rechazó la propuesta, ya que Inglaterra buscaba un aliado continental contra Rusia $^{33}$. Aunque Alemania pudo concluir un acuerdo con los británicos que le permitía tener un derecho sobre las posesiones coloniales de Portugal (ya que era posible que empeñara sus colonias por dificultades financieras). El Tratado de Angola del 30 de agosto de 1898, preveía una repartición de Angola, Moçambique y Timor entre ambas potencias; para lograr esto Alemania le retiraba el apoyo a los boers y se comprometía a no intervenir en el futuro en Sudáfrica ${ }^{34}$.

Los boers eran colonos, campesinos holandeses que tenían control de algunas zonas de Sur África y al encontrarse oro en Transvaal los británicos reclamaron derechos y llegaron contingentes de colonos Ingleses. Esto inicia las tensiones en las relaciones entre Gran Bretaña y Alemania, el resultado es que "se sospechaba del otro". El káiser felicitó al presidente del Estado independiente de

32 Mommsen, Wolfgang J. Op.Cit., pág. 145

33 MacMillan, Margaret. 1914. De la paz a la guerra. Madrid: Turner Publicaciones S.L. 2013, pág. 74.

34 Mommsen Wolfgang J. Op.Cit., pág. 150 y MacMILLAN, Margaret, Op.Cit., págs. 86-87. 
Transvaal a raíz de la victoria afrikáner o boer contra los ingleses, esta acción molestó al gobierno y a la opinión pública ingleses ${ }^{35}$.

En el Extremo Oriente, Alemania en China obtuvo el arriendo forzoso de Tsingtao, tomada a la fuerza en 1897, esto facilitó la repartición del territorio chino, Alemania buscaba "su lugar bajo el sol". Hacia 1900 Alemania e Inglaterra firmaron el tratado del Yangtse, por el cual respetaban sus áreas de influencia y se comprometían a mantener la situación de China bajo una aparente estabilidad, pero esto significó el paso de nuevas discordias ${ }^{36}$.

En ese proceso de equilibrios los eslavos de la península balcánica afectaron los acuerdos, por ejemplo, los líderes rusos tenían presente la anexión de Bosnia y Herzegovina por el imperio austrohúngaro en 1908. Rusia no había respaldado a Serbia cuando esta se enfrentó al imperio austrohúngaro en las guerras de los Balcanes de 1912-1913. El imperio austrohúngaro amenazaba con destruir a Serbia en 1914 después del asesinato de Francisco Fernando Archiduque de Sarajevo; Alemania le había dado su respaldo al imperio austrohúngaro. Ya era ya difícil resolver la situación como en las crisis anteriores a propósito de las colonias o en los Balcanes.

El imperio austrohúngaro temía desaparecer como potencia si no actuaba contra el movimiento nacionalista sudeslavo que pretendía una Serbia independiente. Francia temía a su vecino alemán, más fuerte económica y militarmente. Alemania se preocupaba porque Rusia se estaba desarrollando y rearmando a gran velocidad. A Gran Bretaña la beneficiaba el mantenimiento de la paz, pero cada potencia temía a las otras, pero también temía a su propio pueblo. En Europa los sindicatos, los partidos socialistas y comunistas desafiaban el poder de las viejas clases dominantes ${ }^{37}$.

\section{Circunstancias previas a la Guerra Total y el mundo colonial}

La muerte de la reina Victoria y el ascenso de Eduardo VII significan un cambio en las relaciones internacionales de Gran Bretaña. Los cambios se derivan en parte por la guerra de los boers en Sudáfrica; además las elecciones celebradas en el otoño de 1900, se convocaron bajo el signo del imperialismo, se afirmaba que "todo escaño ganado por los liberales, es un escaño ganado por los boers". Al final se da el triunfo del gobierno conservador que había iniciado esa guerra. Los súbditos del nuevo rey ponen en duda el valor del Credo imperialista, al iniciarse la guerra (1898), se denunciaba la ilegitimidad de la acción en contra de la independencia de los territorios boers Transvaal y Orange ${ }^{38}$.

Los boers causaron grandes pérdidas en las tropas británicas; para debilitar a los rebeldes el mariscal Lord Roberts quema los cultivos y encierra a los habitantes en campos de concentración. En 190 I un 12\% de sesenta mil boers mueren, al igual que la mitad de los niños. Esto impacta a los más

35 MacMillan, Margaret. Op.Cit., pág.86.

36 Mommsen, Wolfgang J. Op.Cit, pág. 154.

37 MacMillan, Margaret. Op.Cit., pág. 19-22.

38 Chastenet, Jacques. Churchill y la Inglaterra del siglo XX. Barcelona: Ediciones Ariel. 1957, págs. 20-2I. 
imperialistas de Londres, además, los boers son blancos y no son parte de una raza inferior. Inglaterra ve desaparecer su "aislamiento", a pesar de que ninguna potencia apoyó materialmente a los boers 39.

Hay varias situaciones que van a afectar ese "aislamiento" y que conducirán a las potencias de Europa a la guerra. La primera, es la competencia que los productos de la industria alemana hacen a los ingleses en los mercados internacionales, y en segundo lugar, el rápido progreso de la marina militar de los alemanes. La flota comercial inglesa está dedicada al transporte de mercancías y de tropas al África del Sur. Los mercados abandonados por los ingleses son cubiertos por los alemanes con mercancías a más bajos precios. Para 1900 se propone que la flota naval del Reich sea la segunda más importante del mundo y le compite en el Mar del Norte a la británica. Hacia 1902 son evidentes las posiciones anti-alemanas en Gran Bretaña ${ }^{40}$.

Es necesario precisar que la industria, la fabricación y exportación de máquinas mostraba el poder de los países; hacia 1880, Inglaterra, Estados Unidos y Alemania eran los principales exportadores, en 1913 Alemania era el principal país en ese campo; mientras que los Estados Unidos construían la mitad de la maquinaria industrial del mundo, Alemania una quinta parte e Inglaterra una octava. En los inicios del siglo XX, Inglaterra tenía un $21 \%$ del comercio mundial, Alemania iba con un I2\%, Estados Unidos en tercer lugar, con un 1 I\% y Francia con un $8 \%{ }^{41}$.

El Iro de junio de 1902, los últimos grupos boers deponen las armas, y las paz se firma en Vereeniging, Transvaal y Orange pierden su independencia, pero sus habitantes conservan el uso de su idioma y se les permite tener instituciones representativas, reciben tres millones de libras esterlinas como indemnización. Posteriormente, los generales boers Botha, Delarey y de Wet van a Londres a ultimar los detalles de la paz y son recibidos de una manera entusiasta. La fiebre imperialista se ha perdido y la mayoría de británicos no están satisfechos con una victoria que les ha costado 250 millones de libras esterlinas y 22 mil muertos ${ }^{42}$. Aquella guerra demostró cuán impopulares eran los británicos en gran parte del mundo ${ }^{43}$.

Las armas y su perfeccionamiento tecnológico (el rifle de repetición), el saqueo, la compra-venta de seres humanos, los intercambios comerciales, produjeron, la desestabilización del continente. Cuando se reparten a África, los británicos entre 1906 y 191। establecieron la prohibición de venta de armas y, para ese año, se estimó que once millones de fusiles europeos habían entrado en ese continente desde 1860.

El verdadero motivo que tuvo Inglaterra para abolición de la trata de esclavos en I897, fue el de acabar con la Compañía Alemana del África Oriental de Kart Peters y, evitar que participara en

39 Ibídem, pág. 22.

40 Ibídem, pág. 23, Mommsen, Wolfgang J. Op.Cit., págs. 214-216; BRUUN, Geoffrey. La Europa del siglo XIX (I814-19|4).México: Fondo de Cultura Económica. 1993, págs. 236-237.

4I Bruun, Geoffrey. Op.Cit, págs. I52- 153.

42 Chastenet, Jacques. Op.Cit., pág. 25.

43 MacMillan, Margaret. Op.Cit., pág. 51. 
el nuevo reparto colonial de finales de siglo. Los británicos permitieron que los árabes desarrollaran ese comercio humano, ya que podía ser legal la trata interna, porque según para los occidentales esto era inherente al Islam. Se pasa de la Abolición, a fines del XIX, a una reesclavización de los africanos sin gastar en su exportación ${ }^{44}$.

Las aspiraciones imperiales no desaparecen, la corona británica no deja sus políticas militares de conquista y de ampliarse a costa de la inferioridad bélica de otros pueblos. El Sudán egipcio queda bajo el poder inglés, en el oriente el protectorado de la Costa de Somalia se convierte en colonia. Los establecimientos de la costa en Zanzíbar en 1896 son transferidos a la corona y luego se ocupa el interior del país y se construye el ferrocarril, en 1904 esta zona adquiere el nombre de colonia del África Oriental Británica (luego Kenya y Uganda); Costa de Oro (Ghana) es sometida derrotando a los ashantis.

En Asia, el virrey de las Indias, Lord Curzon, estableció un protectorado sobre la mayoría de sultanatos del Golfo Pérsico y lanzó una expedición al Himalaya hacia el Tibet, en agosto de 1905; el Gran Lama de Lhassa fue obligado a aceptar la protección y la influencia británica. Al tiempo, los acuerdos de 1904 con Francia, permitieron que Inglaterra tomara el oriente del Golfo de Siam y lograra la ampliación de las colonias de Malasia ${ }^{45}$.

Los súbditos de las Self-governing colonies (colonias pobladas de blancos) como Canadá, Nueva Zelanda y Australia, esperaban contar con un parlamento imperial que las articulará con la metrópoli. En la guerra anglo-boer manifestaron su lealtad y mantuvieron su autonomía después de la conferencia colonial en Londres en 1902. Las Self-governing colonies aceptan gobernadores ingleses, su política fue dirigida por el Foreign Office, luego adquieren la condición de Dominio (1907) y Sudáfrica la tiene en $1910^{46}$.

En el año de 1910 muere el rey Eduardo VII, asciende el nuevo monarca Jorge $V$ y se dan grandes cambios, entre ellos la expansión comercial e industrial de Alemania y Estados Unidos, la implantación de industrias en países que anteriormente eran importadores. Ocurre una sustitución de recursos energéticos, se pasa de la fuerza térmica (del carbón) a la energía eléctrica, todo esto causa un gran malestar a Gran Bretaña.

En la primera década del siglo XX, el país de Jorge $\vee$ sigue siendo "el primer banquero, el primer armador, el primer asegurador del mundo; cierto que su producción carbonífera aumenta y que el valor global de su comercio exterior progresa, y que el equilibrio de su balanza de pagos está ampliamente asegurado"; pero muchas industrias están en una situación difícil, el desempleo aumenta, el costo de vida sube un 10\% y los salarios se deterioran. La clase obrera se organiza en nuevos sindicatos de trabajos no calificados, cuya agitación es mayor frente a las viejas organizaciones Trade Unions (sindicatos obreros), además aumentan las huelgas y algunas se acompañan de la violencia. ${ }^{47}$

\footnotetext{
44 García CantúS, Dolores. Op.Cit., págs. 63-64.

45 Chastenet, Jacques. Op.Cit., págs. 37-38.

46 Ibídem, pág. 38.

47 lbídem, pág. 55.
} 
Es interesante recordar que la Primera Guerra Mundial se inició en la colonia alemana de Togo en el África Occidental. A miles de kilómetros del Frente Occidental de Europa, en agosto de 1914, comenzó la Primera Guerra Mundial, una colonia que los alemanes perdieron en unas pocas semanas. La razón: la estación de telégrafo de Kamina, centro neurálgico de las comunicaciones, sin terminar la construcción se transmitieron más de 200 de mensajes previos a la confrontación (unía a Berlín, África y el Océano Indico).

La derrota se facilitó porque esa colonia estaba rodeada por los enemigos aliados, ingleses al oeste y franceses al norte y al este, además no había unidades militares alemanas, los soldados eran del África Occidental, había que recurrir a la policía que tenía 500 efectivos y muchos mercenarios de otros países comandados por dos oficiales alemanes. Fue la primera victoria de los aliados en la guerra y en sus colonias, allí los germanos estuvieron 30 años y se fueron en varias semanas, curiosamente como herencia colonial en la actualidad se le enseña a los togoleses el idioma alemán ${ }^{48}$.

El colonialismo gradualmente contribuirá al despertar del nacionalismo en el continente africano, sumado a lo anterior se reclutaron ejércitos en África. Un millón de soldados combatieron en la Primera Guerra Mundial y otros segmentos de la población como niños y mujeres fueron vinculados para apoyar a los ejércitos europeos. Más de 150.000 soldados africanos murieron en la guerra.

Los pueblos de las colonias africanas y asiáticas de las potencias europeas -57 millones de habitantes de las colonias francesas, 434 de las inglesas, 15 de las belgas y 12 de las alemanas- se involucraron en la guerra; 398 millones de habitantes de los países europeos y 5 I 8 de las colonias estaban envueltos en la guerra a los diez días de su comienzo ${ }^{49}$.

"La derrota del poder colonial alemán, a la que contribuyeron los africanos, aceleró la toma de conciencia sobre el potencial de sus propias luchas. El blanco y su poder colonial no eran invencibles; sin embargo, las excolonias alemanas pasaban a otras manos y no obtenían su independencia. Se las repartían los poderes europeos vencedores. A Francia y Gran Bretaña les correspondió Togo y el Camerún, el suroeste africano alemán a la Unión Sudáfrica, y el África oriental alemana a Gran Bretaña y a Bélgica que recibió Rwanda y Burundi” 50 .

Después de la Segunda Guerra Mundial, se dará el proceso que haría convertir las peticiones de los nacionalistas, de una mayor participación en el proceso de gobierno, en exigencia de un control total del territorio africano, así se iniciaría la liberación nacional.

48 BBC en español. Togo, el lugar donde empezó la Primera Guerra Mundial. http://www.bbc.co.uk/mundo/video_fotos/2014/10/14100I_video_guerra_mundial_togo_Ip Consulta: julio 23 del 2014

49 Manusevich, A. La Primera Guerra Mundial. Buenos Aires: Editorial Cartago. 1965, pág. 22.

50 Pérez Ramirez, Gustavo. Mirar hacia África. Imperativo del diálogo sur-sur. Bogotá: Plaza\&Janes - Servicio Colombiano de Comunicación SCC. 1989, pág. 60. 


\section{El paso del siglo $X \mid X$ al $X X$ y validación del sistema colonial}

En las últimas décadas del siglo XIX se dan fuertes transformaciones en las relaciones entre las potencias europeas, las políticas imperialistas hacen parte de los gobiernos. Gradualmente la vieja diplomacia que no se interesaba por colonias y nuevos mercados en ultramar, fue cambiando, y aumentaba el interés por los problemas coloniales mientras la política europea pasaba a un segundo plano.

Hacia 1875 los países europeos dominaban el I I\% del territorio africano, en 1902, su dominio se había extendido al 90\%. En el norte de África en 1880, en Argelia, Egipto y Tunicia existían algunas formas de control europeo; en el resto del continente, sólo en Senegal y Costa de Oro (Ghana) habían administraciones coloniales, el resto de regiones eran enclaves comerciales -que no eran colonias-, incluidos los territorios de Angola y Moçambique. Tres décadas después, las potencias de Europa tenían la soberanía sobre las cuarenta unidades políticas en que habían dividido el continente africano ${ }^{5 !}$.

El siglo XIX significó el fin de la esclavitud que hizo parte de esa expansión capitalista, en esa época predominaba la actividad por los árabes en la costa oriental y el interior de África para venderlos en el norte del continente y en el Índico, a cambio de textiles (indias al principio, telas británicas después) barras de hierro, armas y alcohol; productos, estos dos últimos, que les fueron muy útiles a los europeos en su "caza del negro".

Los grandes beneficios los obtuvo la burguesía europea y estadounidense gracias a la mano de obra esclava -"forzosa"- en plantaciones, minas y demás explotaciones que proporcionaban las necesarias materias primas baratas para el desarrollo de la Revolución Industrial (v.g. el algodón). El comercio de esclavos beneficiaba a una burguesía industrial -textil, siderúrgica naval, monopolios de productos de abastecimiento, etc.-, y también a una burguesía especulativa: los sectores aseguradores y prestamistas (agencias y bancos). Y, además, la burguesía -que había amasado su fortuna en las colonias a base de la propiedad y explotación de grandes latifundios de productos monoexportadores trabajados por esclavos- reinvertía el capital acumulado en la industria del textil, del tabaco y de las navieras ${ }^{52}$.

La esclavitud atlántica fue legal hasta mediados del XIX. El país que más se benefició de ella desde el Tratado de Utrech de 1713 fue Inglaterra, quien abolió el tráfico en sus colonias -más no la esclavitud- con la Abolition Act de 1807, ya que Gran Bretaña entró en la fase de libre mercado. En África, se buscó la abolición pretendiendo que las tribus playeras dejasen el comercio para dedicarse a los cultivos agrícolas monoexportadores (algodón, cacao, caucho etc.) y a la obtención de aceite de palma (necesario para la maquinaria industrial), marfil, maderas, añil, oro, etc. Pero Inglaterra encontró resistencia tanto de los gobiernos como de los pueblos nativos africanos ya que gracias a

5 I Madrilejos, Mateo. Op.Cit. págs., 24-25.

52 García Cantús, Dolores. "El tráfico de esclavos y la esclavitud a la base del surgimiento y desarrollo del sistema capitalista" En: Anaquel de Estudios Árabes 53, 2008, vol. 19, pág., 57.

http://revistas.ucm.es/index.php/ANQE/article/viewFile/ANQE0808। I0053A/3559

Consulta: enero 14 del 2014 
la trata podían acumular mercaderías y tecnología occidentales. Durante varias décadas los pueblos costeros continuaron abasteciendo de esclavos a la costa occidental african ${ }^{53}$.

Hacia fines de siglo, con el cierre del proceso de Abolición, que buscaba la eficacia en el trabajo y productividad de los ex esclavos, las metrópolis, en cabeza de Alemania inician el reparto del "pastel africano" realizado a partir de 1885 (Conferencia de Berlín), y reaniman la administración directa de sus colonias, es decir, a una interpretación de las leyes basadas en la inferioridad de los súbditos de ultramar. Las nuevas políticas imperiales y la aplicación del libre mercado a los países colonizados, determinaron la muerte de posiblemente 40 millones de seres de 1867 a $1902^{54}$.

La nueva fase de la Revolución Industrial condujo al establecimiento de formas monopolistas de poder económico, asociadas al imperialismo y a los imperios coloniales. Los puertos, los fuertes y las factorías que sirvieron para el comercio y el tráfico de esclavos, ya no eran suficientes, el poder comercial cedía el paso al poder industrial -y financiero, que se iba configurando-. En parte, los esfuerzos buscaban materias primas baratas para la industria europea y facilitar salidas al exceso de manufacturas ${ }^{55}$.

A principios del siglo XX, el 90\% aproximadamente de África y el 95\% de Oceanía se encontraban bajo la dominación europea, aunque solamente una cuarta parte de la población vivía en Europa. África fue colonizada por agentes especializados y colonos, a excepción del extremo meridional y algunas zonas del norte de África.

La división territorial de África se basó en intereses económicos sin que se consideraran los factores culturales; esta división constituyó la raíz de los enfrentamientos entre las antiguas potencias coloniales. El fenómeno colonial fue un fuerte estímulo de las dos guerras; en los periodos de postguerra se buscaron soluciones al problema del colonialismo, en el primer momento con el establecimiento del sistema de mandatos bajo la supervisión de la Sociedad de Naciones (1919-1946). En el segundo periodo mediante la abolición de la idea de "colonia" y su reemplazo por el concepto de territorios no autónomos y fideicomisos, los cuales pretendían la autonomía completa. Mientras que la Sociedad de Naciones reguló jurídicamente la institución colonial, las Naciones Unidas establecieron las bases jurídicas de la descolonización ${ }^{56}$.

Al finalizar la Primera Guerra Mundial, el empleo de soldado y mano de obra "coloniales" y la demanda de materias primas para sostener el conflicto, habían producido para 1918, algunos cambios en el statu quo de ese colonialismo. Entre esos está el movimiento internacional que representó la Revolución Rusa (Revolución Bolchevique) de 1917; además, el reconocimiento de las nacionalidades europeas ejercía efectos en los pueblos fuera de Europa, que tenían culturas más antiguas.

53 Ibídem, págs.57-6I.

54 Ibídem, p. 62 y Bormann, Martin. Op.Cit., págs. 61-63.

55 Cuadra, Héctor. La polémica sobre el colonialismo en las Naciones Unidas. México: Universidad Autónoma de México. 197I, pág. II.

http://artepepan.com.mx/homenaje_hectorcuadra/publi/Laspolemicasobreelcolonialismoenlasnacionesunidas.pdf Consulta: enero 14 del 2014.

56 Ibídem, pág. 12. 


\section{Palabras de cierre}

I- A pesar de los enfrentamientos y de las diferencias que habían entre los británicos y los alemanes sobresalían los elementos de acercamiento y encuentro, su procedencia y referencia era Occidente. "Las semejanzas entre alemanes e ingleses demostraban que los dos pueblos formaban parte de la raza teutónica, que compartían los mismos valores de sensatez y sobriedad, y que tal vez siempre había sido así". En la historia ambos grupos -continental e insular- habían resistido al ImperioRomano, y a lo largo de los siglos habían creado sus propias instituciones políticas y sociales. La religión, era otro punto de unión; en ambos países las élites eran en buena medida protestantes.

"Cada uno encontraba mucho de admirable en el otro. Los británicos admiraban la cultura y la ciencia alemanas. Las universidades y escuelas técnicas alemanas se convirtieron en modelos para los educadores británicos. Los estudiantes de esta nacionalidad de materias tales como la medicina tenían que aprender alemán para poder leer los últimos trabajos científicos. Los alemanes dominaban disciplinas importantes, como los estudios bíblicos y la arqueología; y la historia alemana, con su énfasis en el trabajo de archivo, la acumulación de datos y el uso de pruebas, daba la impresión de mostrar el pasado "tal como fue en realidad". Por su parte, los alemanes admiraban la literatura inglesa, especialmente a Shakespeare, así como el modo de vida británico" 57 .

Había muchos vínculos, desde matrimonios hasta asociaciones de negocios en las ciudades del otro país. En la nobleza había parentesco y cercanía con el otro lado. La reina Victoria descendía de dos familias reales alemanas, los Hannover y, por parte de madre, los Sajonia-Coburgo, además estaba emparentada con casi todas las familias gobernantes de Alemania ${ }^{58}$.

Las diferencias se expresarían entre Alemania y Gran Bretaña en la Gran Guerra; se manifestaba un conflicto entre una potencia global que veía desvanecerse su ventaja y el auge de un rival emergente. La potencia hegemónica desconoció a los países que reclamaban un espacio en la política internacional y predicaba al resto del mundo cómo administrar sus asuntos, y desconocía las preocupaciones de las potencias menores. Gran Bretaña por entonces, se resistía a reconocería su decadencia, y la nueva potencia quería tener parte de ese mercado mundial, ya fuera con colonias, comercio, recursos o influencia.

En el siglo XIX, Gran Bretaña poseía el mayor imperio del mundo y dominaba los mares y el comercio internacional, por eso, rechazaba las aspiraciones de las demás naciones fueran Alemania, Rusia o Estados Unidos. Gran Bretaña presumía de su superioridad, por ejemplo, con sus instituciones y de su política sobre las del continente, e intervenía en los conflictos cuando vislumbraba alguna ganancia para sí. En su expansión colonial, los británicos argumentaban que solo se apropiaban de

57 MacMillan, Margaret. Op.Cit., pág. 83.

58 lbídem, págs. 83-84. 
nuevos territorios en aras de asegurar los que ya poseían, o bajo una actitud filantrópica hacia los pueblos sometidos, mientras que la motivación de las otras naciones era la codicia ${ }^{59}$.

Alemania se mostraba como una potencia mundial emergente y deseaba participar de las decisiones mundiales. Era un país grande en el centro de Europa, y económica y militarmente más fuerte, que sus vecinos. Su comercio se expandía, compitiendo cada vez más con el de Gran Bretaña; carecía de colonias, que, junto a las bases navales, las explotaciones de carbón y los servicios de telégrafo, constituían los rasgos distintivos de una potencia global. Además, cada vez que intentaba incorporar territorios de ultramar, en África, Gran Bretaña se oponía. Cuando el nuevo ministro de Asuntos Exteriores, Bernhard von Bülow, pronunció su discurso en el Reichstag en I897, en el que decía que «Alemania reclamaba su lugar bajo el sol», fue muy bien recibido por sus compatriotas ${ }^{60}$.

En ese momento los imperialistas británicos reclamaban la necesidad de incorporar todavía más territorios para proteger los que ya tenían, así como las rutas marítimas y telegráficas. Su producción industrial, era importante aunque en una proporción menor con respecto al total mundial, debido a que nuevas potencias como Alemania y Estados Unidos le estaban dando alcance, y otras viejas como Japón y Rusia se estaban incorporando aceleradamente a la era industrial.

En las décadas previas a la Primera Guerra Mundial hubo tensiones entre Gran Bretaña y Alemania, se sospechaba del otro. El primer incidente, como ya se señaló, fue el reconocimiento del Káiser en 1896 al presidente del Estado independiente de Transvaal (república boer) por la victoria contra las tropas británicas, esto provocó rechazo en Gran Bretaña, así fue el comienzo de la división entre Gran Bretaña y Alemania.

2- El intelectual africano Ndabaningi Sitholi a mediados del siglo XX revisaba el papel del colonialismo europeo en África, y afirmaba
"civilizar a un pueblo primitivo significa salvar la distancia que media entre el ci- vilizado y el incivilizado. En otras palabras, elevar al hombre primitivo al nivel del civilizado", eso conlleva que al civilizar un pueblo se busca "crear una comunidad de pensamientos e ideas en la que participan el portador de la civilización y el que se inicia en la misma". Esto significa "que el proceso de civilizar a un pueblo primitivo es equivalente a la liquidación de la posición monopolizadora de quienes se dedican a civilizar a los demás"6l.

El imperialismo europeo le dio un gran impulso al nacionalismo africano, las potencias europeas alcanzaron en parte los objetivos que se habían propuesto, ya "que el pueblo de ese continente desea alcanzar el mismo nivel que el de las potencias europeas que se lanzaron a civilizarlo". Al desaparecer la institución de la esclavitud, se les dio una nueva dignidad humana a los esclavos que eran

\footnotetext{
59 Ibídem, pág. 84.

60 Ibídem, p. 86; Ferro, Marc. La Gran Guerra 19/4/19/8. Madrid: Alianza Editorial. 1970, pág. 48

61 Sitholi, Ndabaningi. El reto de África. México: Fondo de Cultura Económica. 1961, pág. 84.
} 
propiedad de otros, las potencias coloniales, además de alguna forma la presencia del extranjero supuso la eliminación de las guerras tribales ${ }^{62}$, pero que volverían con fuerza después de la luchas de liberación (años 60).

El colonialismo significó un menosprecio de lo tribal -que hoy en día se trata de recuperar-, las potencias coloniales ayudaron a la destribalización. El colonialismo impuso en las ciudades los lazos socioprofesionales sobre los lazos tribales, "el nivel de vida y la instrucción se sobreañaden a las divisiones étnicas del interior de los barrios negros" ${ }^{\prime 3}$. Una nueva esfera de intereses se creó con la colonización, aparecen los nacionalismos, al decir de Sitholi "existe entre los africanos una tendencia creciente a considerarse cada vez menos como miembros de una tribu y cada vez más como africanos" ${ }^{64}$, esto nos lleva a la contraparte y es que hay más preocupación por reconocer los nacionalismos de los europeos pero no los de los otros.

3- Es interesante observar que la acción de la "supremacía blanca" no se limitó a los procesos de colonización y de colonialismo que se dieron por parte de los europeos en África y Asia, sino que se presentó en otras latitudes del planeta, además persistió -y lo sigue haciendo- a lo largo del siglo $X X$, este será uno de los más fuertes cuestionamientos desde la Interculturalidad.

En el año de 1972 el líder guineano Amilcar Cabral que confrontó al último poder colonialista en África, el de Portugal (que finaliza en 1974), mostró cómo la colonización bloqueó el proceso histórico del desarrollo de los pueblos y cómo el imperialismo impuso nuevos tipos de relaciones en las sociedades autóctonas. "El capital imperialista introdujo, con el ciclo de la moneda y el desarrollo del mercado interior y exterior, nuevos elementos en la economía, lo que originó el surgimiento de nuevas naciones a partir de grupos humanos o de pueblos que se hallaban en diferentes fases del desarrollo histórico"65.

En los movimientos de liberación a lo largo del siglo XX la cultura adquiere una gran importancia, y para Cabral fue "una contribución útil a la lucha general de los pueblos contra la dominación imperialista", es un elemento clave en la resistencia de las masas populares frente a la dominación extranjera. Frente a las políticas de los países europeos, la única solución para contrarrestar la resistencia cultural del pueblo colonizado es la "asimilación", pero que en la práctica fue una teoría falsa, ya que la ocupación cultural del extranjero se dio en la capital, algunas ciudades en los puertos y en las costas. La influencia cultural es nula en otras zonas, por eso señala Cabral

"He ahí la razón de que a las masas populares no se les plantee, ni pueda planteárseles, el problema del «retorno a las fuentes» o del «renacimiento cultural»: las masas son las portadoras de la cultura, ellas mismas son la fuente $y$, al mismo tiem-

\footnotetext{
62 Ibídem, pág. 86.

63 SARTRE, Jean Paul. "El pensamiento político de Patrice Lumumba" En: Colonialismo y Neocolonialismo. Situations V. Buenos Aires: Editorial Losada. 1968, pág. I5I.

64 Ibídem, pág. 89.

65 Cabral, Amilcar. "La cultura fundamento del movimiento de liberación” En: El Correo de la Unesco. Noviembre 1973, pág. 12.
} 
po, la única entidad verdaderamente capacitada para preservar y crear la cultura, es decir, para hacer historia"66.

Por eso, la cultura es el fundamento de la liberación y sólo pueden luchar contra la dominación extranjera aquellas sociedades que preservan su cultura, claro está que la cultura tiene particularidades y no es uniforme en las sociedades. Es posible un reconocimiento de que el pueblo colonizado y en lucha posee una identidad y una cultura propias, que les posibilita su derecho a la autodeterminación y a la independencia ${ }^{67}$.

"...la cultura-creación de la sociedad y síntesis de los equilibrios y soluciones que engendra para resolver los conflictos que la caracterizan en cada fase histórica- es una realidad social independiente de la voluntad de los hombres, del color de su piel, de la forma de sus ojos o de los límites geográficos de cada país".

Amilcar Cabral precisa que a los pueblos no les debe preocupar demostrar la especificidad de su cultura, sino tener un análisis crítico de esa cultura, para ser parte de una civilización universal, como parte del patrimonio común de la humanidad y su articulación al mundo actual68.

\section{Bibliografía}

BORMANN, Martin. Entre la cruz y el fetiche. Barcelona: Plaza \& Janes. 1968.

BRUUN, Geoffrey. La Europa del siglo XIX (18/4-19|4). México: Fondo de Cultura Económica. 1993,

CABRAL, Amilcar. "La cultura fundamento del movimiento de liberación" En: El Correo de la Unesco. Noviembre 1973, págs. 12-20.

CHASTENET, Jacques. Churchill y la Inglaterra del siglo XX. Barcelona: Ediciones Ariel. 1957.

CUADRA, Héctor. La polémica sobre el colonialismo en las Naciones Unidas. México: Universidad Autónoma de México. 1971.

http://artepepan.com.mx/homenaje_hectorcuadra/publi/Laspolemicasobreelcolonialismoen lasnacionesunidas.pdf

Consulta: enero 14 del 2014.

FERRO, Marc. La Gran Guerra 19/4/19/8. Madrid: Alianza Editorial. 1970.

FIELDHOUSE, D.K. Economía e Imperio. La expansión de Europa. México: Siglo Veintiuno Editores. 1977

GARCÍA CANTÚS, Dolores. "El tráfico de esclavos y la esclavitud a la base del surgimiento y desarrollo del sistema capitalista" En: Anaquel de Estudios Árabes 53, 2008, vol. 19, págs. 53-55.

66 Ibídem, pág. 14.

67 Ibídem, pág. 15.

68 Ibídem, pág. 20. 
http://revistas.ucm.es/index.php/ANQE/article/viewFile/ANQE0808 I I 0053A/3559

Consulta: enero 14 del 2014

GONZÁLEZ CASANOVA, Pablo. "Colonialismo interno, una redefinición" en La teoría marxista hoy, problemas y perspectivas, Borón, Atilio; Amadeo y González (comps.), Clacso, Buenos Aires, 2006.

GUTIÉRREZ CONTRERAS, Francisco. Nación, nacionalidad, nacionalismo. Barcelona: Temas Clave Salvat. 1980.

LENIN, V.I. Imperialismo fase superior del capitalismo. (Ensayo popular). Pekín: Ediciones en Lenguas Extranjeras, 1975.

MacMILLAN, Margaret. 19/4. De la paz a la guerra. Madrid: Turner Publicaciones S.L. 2013.

MANUSEVICH, A. La Primera Guerra Mundial. Buenos Aires: Editorial Cartago. 1965.

MADRILEJOS, Mateo. Colonialismo y Necolonialismo. Barcelona: Salvat Editores. 1975.

MOMMSEN, Wolfgang J. La época del Imperialismo. México: Siglo Veintiuno Editores. 1978.

PÉREZ RAMIREZ, Gustavo. Mirar hacia África. Imperativo del diálogo sur-sur. Bogotá: Plaza\&janes - Servicio Colombiano de Comunicación SCC. 1989.

RUBIO, Rocío. Imperialismo y colonialismo. Bogotá: Editorial Voluntad. 2003.

SÁNCHEZ RODRÍGUEZ, Jesús (20 I4). 19I4. EL QUIEBRE DE LA HISTORIA. Causas y consecuencias de la primera guerra mundial, págs. 39-4I.

http://www.rebelion.org/docs/ / 86878.pdf

Consulta: julio 23 del 2014

SARTRE, Jean Paul. "El pensamiento político de Patrice Lumumba" En: Colonialismo y Neocolonialismo. Situations V. Buenos Aires: Editorial Losada. 1968,

SITHOLI, Ndabaningi. El reto de África. México: Fondo de Cultura Económica.

WALSH, Catherine. Interculturalidad, Estado, sociedad luchas (de)coloniales de nuestra época. Quito: Universidad Andina Simón Bolívar / Ediciones Abya-Yala, marzo 2009.

\section{Material Audiovisual}

BBC en español. Togo, el lugar donde empezó la Primera Guerra Mundial. 2004. http://www.bbc.co.uk/mundo/ video_fotos/2014/10/14 I00 I_video_guerra_mundial_togo_Ip

Consulta: julio 23 del 2014 